\title{
Holding Tight to Our Convictions and Lightly to Our Ways: Inviting Shared Expertise as a Strategy for Expanding Inclusion, Reach, and Impact
}

\author{
Kylie Korsnack and Leslie Ortquist-Ahrens
}

\section{Abstract}

When the global pandemic forced campuses across the United States to send students home in March 2020, instructors were thrown into triage mode, forced to rapidly transition their on-the-ground classroom curriculum to a format that could be completed remotely by students spread out across the country. At the same time, centers for teaching and learning (CTLs) also entered triage mode, puzzling over how to quickly but effectively provide appropriate training and meaningful support to prepare faculty for this rapid transition (Aebersold et al., 2020). The situation's urgency, coupled with the significant constraints many CTL directors already experienced, necessitated creative, flexible, and, in some cases, unorthodox approaches to faculty development. This article describes the creation, implementation, and takeaways from our CTL's response to this immense challenge. We retrospectively reflect upon how our center-of-one at a small private liberal arts college with no history of online education was able to build and take a 4-week experimental online training course for 13 faculty members and scale it up so that, by the end of 3 months, 105 participants, or over $80 \%$ of our institution's full-time faculty, had completed a course in online teaching. In doing so, we identify four impactful practices that made our experience possible 
and that have potential future value, especially for small or underresourced centers.

Keywords: center-of-one, collaboration, inclusion, expertise

\section{An Unprecedented Challenge}

On March 10, 2020, the president of Berea College announced that students would be sent home on Saturday, March 14. This decision was not made lightly by the academic leadership council, as it would introduce significant hardship for students and faculty. Berea College's distinctive mission rests on providing access to a high-quality liberal arts education for promising students from the Appalachian region and beyond, all from backgrounds of significant economic need and over $40 \%$ from traditionally underserved groups, particularly Black and Latinx populations. Ninety-eight percent of students are Pell eligible, and each student receives a complete 4-year tuition scholarship, supported by earnings from Berea's endowment. The leadership's reluctance stemmed from awareness that a number of students could not go home or had no home to go to, that some might go to localities with unreliable digital access, and others would find welcoming homes but also increased family and wage-earning responsibilities. The leadership also anticipated that many students could not afford the unanticipated travel costs. For all, the shift to remote teaching and learning was unprecedented, disruptive, and challenging, but for many of our students, it exacerbated existing structural and economic inequalities, creating barriers to learning at a distance.

The college worked to mitigate some of these barriers (providing students with internet hot spots, helping with travel costs, and making it possible for students to apply to remain on campus), and the leadership emphasized that faculty should plan to complete spring courses remotely in a way that allowed every student to participate: "If all [students in a class] have high-speed internet available, you might be able 
to run some whole-class meetings via Zoom. If the best a student can manage is checking email and Moodle at the local library or McDonalds, you will need to use exclusively asynchronous means of communication. Minimal electronic access is reasonable to expect" (L. StrongLeek, M. Saderholm, \& L. Roelofs, campus communication, March 11, 2020).

Out of conviction, like many small liberal arts colleges that prize high-touch, residential educational experiences, Berea College offered no online education. Thus, even if all students in a course had adequate digital access at home, the challenge was enormous in other ways. Faculty underwent nothing less than a sea change in suddenly navigating spring term classes at a distance. More than a few had been spotty users of educational technology, some with little to no familiarity with Moodle, the college's learning management system (LMS), and rare experience with Zoom.

Complicating their preparation, the information technology staff and infrastructure, the single educational technologist responsible for Moodle, and the center-of-one faculty development unit were not designed or resourced to support large-scale remote instruction. They forged a spontaneous partnership to offer instructors several training sessions that highlighted good (enough) pedagogies for remote teaching. Instructors were encouraged, like others nationally, to set modest goals and to conceive of "remote teaching" as "triage." Faculty responded with commitment, ingenuity, and concern for their students. Many students, too, persisted and finished the semester strong, but a significant number struggled with the transition, and the attrition rate was unusually high.

\section{Our Response}

When the college decided to offer May term and summer courses remotely, it became clear to the co-authors, Kylie and Leslie, as educational developers, that more preparation would be critical to help fac- 
ulty move beyond triage. To remain true to Berea's core values and to serve students in this stressful, even traumatic, time (Imad, 2020), those courses needed to be academically solid and to attend to accessibility, inclusion, belonging, and equity in meaningful ways. Yet it was also clear that the new partnership between the center for teaching and learning (CTL) and instructional technology would not suffice to offer such an initiative, as the latter units faced increased demands for software and hardware services and support, leaving little time to collaborate.

As the CTL director, Leslie knew she could not succeed alone. Besides having only basic expertise in online education, she was stretched thin with a 50\% faculty appointment and responsibility for faculty development and directing a unit with a writing center and undergraduate teaching assistant (TA) development. While CTL staff work intentionally to blend visions and practices_including blurring boundaries between teaching and learning and teachers and learners through initiatives such as a Student-Faculty Partnerships programeach is already taxed with their own specific programmatic responsibilities. We recognized, however, that this was a watershed moment. A group came together to brainstorm and to explore an idea: "Could we build and run a month-long online course for faculty who were planning to teach online in May? What complementary expertise did we bring to the table?" Besides the CTL director, the group included the CTL's office manager, the two other CTL staff members-the director of the writing center and the coordinator of TA programs-and two affiliated colleagues: a writing program administrator with a $50 \%$ faculty appointment and Kylie in her role as a Mellon Partners for Humanities Education Postdoctoral Fellow in English, which gave her responsibilities in both the English Department and the CTL. A junior faculty member in philosophy - with over a decade of experience as an ed tech executive and extensive knowledge about online educationvolunteered to participate on top of his full load, and a new digital initiatives librarian in her first year at the college stepped up as well. From this disparate group of colleagues-some who didn't know one 
another at the start-a coherent team of eight developed over the coming month.

The timeline for building and launching was tight. After discussions with the academic leadership to ensure support for the effort, we set to work. The team was left with only 5 days to prepare if we were to achieve our goal of reserving a whole month for the course to unfold. We wanted participants to learn about online teaching through the experience of being online learners themselves, and we also wanted to allow them time, however insufficient, to design their May classes as they went.

To build our Moodle course, we distributed responsibilities to match team members' experience and expertise. As the two educational developers, Kylie and Leslie took the lead on conceiving the learning experience, curating course materials, and building the Moodle site. Drawing on Kylie's graduate school position at Vanderbilt University's CTL where she developed and taught a seminar on online teaching for graduate students, we adopted a community of inquiry model (Garrison et al., 1999), and emerging from Leslie's long-held commitments to collaborative learning for both faculty and students (Cox \& Richlin, 2004; Johnson \& Johnson, 1989), we created a course structure and rhythm anchored in participants' ongoing involvement in two intentionally distinct base groups: (a) a small discussion board group with interdisciplinary colleagues, and (b) a weekly synchronous Zoom consultation group for pairs from the same or adjacent disciplines, co-facilitated by members of our team. We sought to offer participants the flexibility afforded by a primarily asynchronous course (they could complete readings and assignments largely on their own time) while also modeling how incorporating a synchronous component and discussion boards could drive meaningful learning as it built community.

With limited time to introduce participants to relevant content and principles, we chose just three areas we deemed essential regardless of discipline: fostering presence; using principles of backward course design; and designing for clarity, accessibility, and equity. The first 
week's deep exploration of the concept of "presence"—social, cognitive, and teaching (Garrison et al., 1999)—proved transformative for many participants' thinking about the online context. In Week 2, participants revisited or drafted strong learning outcomes, and they engaged in backward design, which was for some their first encounter with the approach. In Week 3, we focused on design considerations related to principles of clarity, accessibility, and inclusivity as well as a series of optional demos and technology consultations. For faculty who had not previously given ample consideration before to access, belonging, and equity, we believed it was essential to center the topics explicitly as participants built courses for their online learners. Finally, we reserved Week 4 for participants to develop their course shells in Moodle, Box, or Teams with feedback from one another and the leadership team.

Developing authentic application tasks for each week was a priority so faculty participants could emerge with their own solid courses for the May term. Thus, for each week, we created a sequence of activities that led participants through a learning cycle related to developing a component for their course: exposure to content, work with content (with feedback), application of content, and reflection on application (with feedback and discussion). The weekly repetition of the learning sequence, synchronous meeting times, and asynchronous due dates modeled the consistency and clarity essential for a positive student experience.

We also capitalized on the strong teaching identities that our participants, as members of a small liberal arts college faculty that prioritizes exceptional teaching, brought to the experience by first building on their prior knowledge. In doing so, we sought to cement a positive self-image and sense of self-efficacy by helping faculty see how much of their existing teaching practices and values could translate into the online environment.

While Kylie and Leslie built the course shell, the other members of the team drew on their own prior experiences with online education to develop resources and plan for roles providing "teaching presence" as discussion board or Zoom group facilitators. The team also worked to 
identify best practices for online teaching from the literature and worked with the college leadership to draft a set of guidelines and requirements that were then distributed to May term faculty by the provost's office. The guidelines (Appendix A), like the course, were rooted in Chickering and Gamson's "Seven Principles for Good Practice in Undergraduate Education" (1987) as well as the literature on online education. Because we had not been charged with the online course (re)design initiative, communicating regularly with the dean and the provost to clarify what it could contribute to the quality of students' learning became another intentional partnership.

As April drew to a close, it dawned on us that summer courses, too, would be online. A new cohort could benefit from our online course, and we set to improving the pilot version. For the second iteration, only four of the original team members were able to continue-Kylie, Leslie, the philosophy professor, and the digital initiatives librarian. While there was less to build from scratch the second time around, the workload increased significantly for the smaller team, especially since the number of participants rose. Nevertheless, May's refined version of the course successfully prepared an additional 22 instructors.

Countless other faculty, anticipating an uncertain fall term that might be virtual, asked if there would be a June course. But by the time June drew near, two more members of the original core team needed to decrease their level of involvement. It was impossible for the remaining two full-time members to run a significantly scaled-up version of this complex, high-touch course.

In conversation with the dean of faculty, Leslie hatched a plan and sought input from the core leadership team. What if four "graduates" from the first iteration who had already taught online in May returned to serve as course coordinators for four more sections in June? They would join and expand the core leadership team to eight and would take responsibility for daily interactions with participants. An additional set of 11 facilitators would be necessary to help with the 37 Zoom consultation groups for pairs or triads. Kylie stayed on to offer Week 3 tech demos and consultations. 
Of the 16 faculty "graduates" invited by the dean, 15 agreed, allowing us to offer four sections of a June course for an additional 80 participants. The new core leadership team consisted of May's team of four (two with smaller roles; Leslie now serving as full-time program administrator) plus the four new course coordinators, who each had responsibility for one section of 20 participants, fielding questions, providing weekly summaries of discussion board themes, and updating each week's course block, among other things. Eleven additional colleagues joined as co-facilitators, who, together with the course coordinators, each committed to co-facilitating three weekly Zoom meetings for participants. To help prepare for the weekly Zoom consultations, the philosophy professor continued on to provide a weekly overview and Q\&A. Those late Friday afternoon sessions for 19 provided an opportunity for checking in, fine-tuning, and troubleshooting, all in a context of community. Finally, at the end of the month, the course coordinators and philosophy professor reviewed each participant's draft course shell and plan.

\section{Gauging Satisfaction and Effectiveness}

End of course surveys revealed a generally strong positive response from participants. In the aggregate across the six sections, when asked about how valuable the program was for helping to develop an online course, $98 \%$ rated it as valuable, with $64 \%$ finding it extremely valuable and $34 \%$ finding it quite valuable. Ninety-nine percent said they were either extremely likely (78\%) or quite likely (21\%) to recommend the experience to a colleague.

A number of themes emerged in response to open-ended questions. Participants emphasized how much they had learned, that they had gained a greater understanding of how online teaching could be done well, and that they valued having learned with others. They highlighted "presence" together with designing for "belongingness," for transparency, and for accessibility. Overall, the experience helped 
relieve their initial anxiety. Some even expressed excitement at the chance to reinvigorate their pedagogy.

Other metrics indicating success remain anecdotal: participation was fueled by word-of-mouth recommendations, the currency of the realm in the small liberal arts college context; many participants emailed spontaneously with their positive experiences; a few, unsolicited, even forwarded student evaluations. Members of several fall panels held to showcase instructors' summer and fall successes and to brief the board of trustees highlighted students' high level of engagement, in stark contrast to the spring's experience.

A final indication of effectiveness came in September, when the college received an unexpected mandate to formally apply for approval from the Southern Association of Colleges and Schools Commission on Colleges (SACSCOC), our accrediting body, to continue to offer distance courses in spring 2021 after expiration of the emergency approval. Despite having had no previous online or distance learning offerings, the approval was granted largely on the basis of documentation of our work.

\section{Lessons Learned}

There is much we would do differently, knowing what we know now. But given our constraints, we also see what we were able to accomplish, and we recognize four impactful practices or lessons from this experience.

\section{Lean in to Unexpected or Unconventional Partnerships and Collaborations}

Without seizing the opportunity to lean in to unexpected, serendipitous, and unconventional partnerships, we would not have been able to develop the pilot in April, much less June's scaled-up version. Instead, with flexible thinking about who had expertise to share, we 
were able to expand a faculty development experience that was unprecedented at our institution, learning the value of a cascading leadership model in the process. The willingness to welcome various levels and forms of expertise emerged from an ethos we have sought to develop in the CTL, especially through programs such as StudentFaculty Partnerships, which pairs students and faculty over a term in pedagogical partnerships based on respect, reciprocity, and responsibility (Cook-Sather et al., 2014) to engage in dialogue around the expertise and perspective each brings. Such groundwork was fundamental to fostering the mindset we needed in this moment.

\section{Chart New Ways to Connect and Communicate}

As our original team formed, the sudden remote working context made clear we needed new tools and practices to effectively collaborate. While we originally chose Microsoft Teams out of necessity and practicality-emails were becoming unmanageable and Teams was a standard download on all of our college-issued laptops-we now realize that this shift to a group messaging platform itself contributed to swift team formation. The medium facilitated a new level of document sharing and encouraged both quick (e.g., through emojis) and extensive indocument feedback. As a result, we interacted frequently, and our work benefited from the contributions of all members of our group.

More unexpected was the chance we were afforded to show up as whole people in Teams and Zoom interactions. The technologies provided an avenue for championing individuals' work, expressing gratitude and enthusiasm for contributions, being playful, and offering support and guidance. We quickly got to know one another deeply and developed the kind of community, connection, and reciprocal sharing of knowledge that solidified the team. As the pandemic lingered and feelings of isolation and loneliness became widespread, our team's regular mediated contact became increasingly valuable and also demonstrated how technology can be leveraged to help cultivate community at a distance. 


\section{Be Open to Letting Go of Orthodoxies, Habits of Mind, and a Cleaving to "Expertise"}

With little time to prepare and with only fractured, distributed expertise, the urgency of our situation also required us to let go of some orthodoxies and habits of mind. Of necessity, we began with an incompletely fleshed-out course, which inevitably left space to add content or components as we went. While the plan for the original course had reflected our commitment to intentional, backward design, and while we would have preferred to have completed the course in advance, we needed to hold the approach lightly-and benefited from doing so. We could tailor the course to meet emergent needs and include examples of participant expertise. Furthermore, in inviting faculty participants to contribute as co-constructors, we needed to hold our own growing "expertise" lightly. We made a conscious decision to foreground our status as relative "non-experts" in online education. We were transparent about our thinking and decisions and vulnerable and open with our mistakes and missteps. This intentional posture enabled us to navigate the inevitable errors we would make and modeled for participants how to risk vulnerability and be transparent with their students, given that most faculty would be teaching online for the first time in just a couple of weeks. We emphasized the importance of humanizing education (hooks, 1994; Salazar, 2013) and of grace and hope for our students and ourselves, especially in this challenging time. Following the murders of George Floyd and other Black citizens by state officials, during the third month of our program, we eased back on curricular expectations to leave time and space for participants to meet and process their thoughts and feelings instead, especially in weekly Zoom meetings. An administrative email from June 3 (Appendix B) to the nearly 100 participants and leaders seized the moment to reflect on our work with and on behalf of all of our students and to urge care of self in a time of a "dual pandemic."

Because our expertise on the core leadership team grew through April and May, letting go and sharing leadership equitably with the 
new members in June, including many with little to no educational development experience, became an exercise in trust and humility as well as a profound learning experience. Kylie and Leslie had made many intentional choices for the Moodle site over the course of 2 months and were initially reluctant to grant others full editing privileges. The eventual decision to do so required a constructive kind of letting go that allowed for creative experimentation and discovery and respected the contributions and talents of the new members of the leadership team.

\section{Welcome Critical Feedback as an Opportunity to Grow}

Though we responded to feedback as much as we could as we went, there were also criticisms in final evaluations that pointed to major shortcomings on our part. Two important critiques related to the original leadership team's (a) disciplinary homes and (b) (blind spots from) social identities. All members of the original team came from humanities fields, leaving STEM colleagues wishing for more disciplinesensitive guidance. A guest presenter in April, additional resources in May, and expanding the team in June with colleagues from many fields including STEM helped us respond to this felt need. We brought relatively homogeneous social identities: five of us were female-identified and all six were cisgender, heterosexual, able-bodied, and white. Four of us identified as Appalachian. We ranged in age from 26 to 58 . The most important criticism we received was a reminder that, even as our collaborative leadership model promoted an inclusive work experience among its members and many participants, our course was not immune from perpetuating forms of exclusion. While we sought to do our homework and build the course on a foundation of equity and inclusion, we did not do enough in Weeks 1 and 2 to center a greater range of scholarly and practitioner voices, particularly the voices of Black, Indigenous, and other people of color. Again, the expansion of the leadership team in June led to a wider representation of identities, but the lesson will stay with us that no matter who is at the table, it's 
important to plan for noticing and including, centering even, voices from those who aren't.

Along with these important lessons, this experience demonstrated to us what is possible. In just 3 months, we scaled up our original cohort of 13 faculty members to 105 participants, or over $80 \%$ of our institution's full-time faculty. The archivist at the college asked for documentation of the program, as the expansive reach of this initiative will make it one of the most influential faculty development opportunities in the history of our institution. However, ours was certainly just one of many such stories of extraordinary and innovative efforts achieved by CTLs and educational developers across the country during an unprecedented challenge.

\section{Acknowledgments}

We offer gratitude to the 116 participants (even those who didn't complete the course), all 19 team leaders, to IS\&S and Educational Technology, the provost's and dean's offices, and especially to the original team: Amy Nichols, Lauren Hall, Rebecca Wheat, Sarah Adams, Jarrod Brown, and Abby Houston. We learned so much from all of you. Special thanks to the Andrew W. Mellon Foundation.

\section{Biographies}

Kylie Korsnack, Educational Developer, Teaching and Scholarship Hub, University of Richmond (VA). Korsnack earned her PhD in Literary Studies from Vanderbilt University, where she also served as a graduate teaching fellow within Vanderbilt's Center for Teaching. Prior to joining the University of Richmond, she worked as a postdoctoral fellow in English and the Center for Teaching and Learning at Berea College. Her current research interests include early career faculty development, inclusive teaching, and digital pedagogy. 
Leslie Ortquist-Ahrens, Director, Center for Teaching and Learning, and Associate Professor of Comparative Literature, Berea College (KY). Over the past 19 years, Ortquist-Ahrens has directed CTLs at two small colleges, earned tenure twice, and helped secure nearly \$1 million in external funding. Her scholarship focuses on faculty learning communities, new faculty programs, founding and leading CTLs at small colleges, student-faculty partnerships, and organizational development. She is a former president of the POD Network (2014-2015).

\section{References}

Aebersold, A., Hooper, A., Berg, J. J., Denaro, K., Mann, D., Ortquist-Ahrens, L., Sato, B., \& Verma, M. (2020). Investigating the transition to remote teaching during COVID-19: Recommendations for campus leaders and centers for teaching and learning. Journal on Centers for Teaching and Learning, 12, 4-25.

Chickering, A. W., \& Gamson, Z. F. (1987). Seven principles for good practice in undergraduate education. AAHE Bulletin, 39(7), 3-7.

Cook-Sather, A., Bovill, C., \& Felten, P. (2014). Engaging students as partners in learning and teaching: A guide for faculty. Jossey-Bass.

Cox, M. D., \& Richlin, L. (Eds.). (2004). Building faculty learning communities [Special issue]. New Directions for Teaching and Learning, 2004(97).

Garrison, D. R., Anderson, T., \& Archer, W. (1999). Critical inquiry in a textbased environment: Computer conferencing in higher education. The Internet and Higher Education, 2(2-3), 87-105. https://doi.org/10.1016/S1 096-7516(00)00016-6

hooks, b. (1994). Teaching to transgress: Education as the practice of freedom. Routledge.

Imad, M. (2020, June 3). Leveraging the neuroscience of now. Inside Higher Ed. https://www.insidehighered.com/advice/2020/06/03/seven-recomme ndations-helping-students-thrive-times-trauma

Johnson, D. W., \& Johnson, R. T. (1989). Cooperation and competition: Theory and research. Interaction Book Company.

Salazar, M. D. (2013). A humanizing pedagogy: Reinventing the principles and practice of education as a journey toward liberation. Review of Research in Education, 37(1), 121-148. http://doi.org/10.3102/0091732X12464032 


\section{Appendix A}

Berea College Distance Learning:

Expectations/Requirements/Recommendations

05/06/2020

\section{7-Week Terms}

The academic content of courses delivered through distance learning should be designed to be academically equivalent to courses offered in a traditional format. As opposed to "contact hours," distance learning courses are to have sufficient "time-on-task" to match the experience that a student would have in the face-to-face model.

Time-on-Task Context: Full-credit 7-week courses should be designed to include approximately 20 hours per week on task (Background: SACSCOC Credit Hours Policy Statement).

\section{Design Guidelines}

The most effective distance learning course design relies on

- Communication-Clear, frequent and transparent.

- Effective course design-Learning outcomes are tightly aligned ${ }^{1}$ with course materials, activities, assignments, assessment, and timely feedback.

- Strong relationships-Commitment to the process will rely on the development of two-way relationships between instructors and students that create a sense of "presence."

- Collaboration-Connections among students are structured by the instructor around course material and projects or discussions.

- Active learning-Course design engages students in active learning (where possible, using multiple media for variety and to deepen learning).

- Short recorded lectures_Lectures, if any, are made in alignment with strong findings from research (e.g., max. 6-minute "minilectures" interspersed with student activity).

1. Throughout the guidelines, active links led to resources and scholarship to support principles.

To Improve the Academy • Vol. 39, No. 3 • Spring 2021 
- Attention to accessibility-Students have options for assessment formats (consider Universal Design for Learning); note: legally, faculty must design for accessibility of all online materials.

- Frequent low-stakes assessments-Faculty provide ongoing feedback and practice, together with higher-stakes assessments (projects or tests) that are appropriate for the medium. Try to avoid highstakes testing that must be proctored.

- Significant asynchronous delivery-Seize opportunities for asynchronous approaches (to accommodate complexities in students' work and home lives). Extensive synchronous activities (e.g., classes with daily 2.5 hours of Zoom meetings) are likely not effective.

\section{Additional Guidelines/Procedures}

- Inform students of your connectivity/technology expectations before the course begins to allow students to find alternative courses as needed.

- Build courses primarily using Berea-supported, FERPA-compliant platforms and tools (Moodle, Zoom, Box, and Teams). Seek guidance from IS\&S before requiring students to sign up for additional applications to ensure that all ethical considerations and issues related to student privacy, safety, remote surveillance, and/or the inappropriate sharing of student data have been taken into account.

- Use platforms and tools with strong track records of accessibility in their design (like Moodle).

- Ensure that all course materials are already in accessible formats or made accessible to students with guidance and/or aid from the Office of Disability and Accessibility Services (contact DAS for assistance).

- Those who typically use high-stakes traditional assessments are encouraged to consider developing alternative assessment strategies and/or using open-book formats with modification (see link on page 1 and/or work with CTL consultants). While there are some tools in Moodle for remote proctoring, there is a learning curve to using

To Improve the Academy • Vol. 39, No. 3 • Spring 2021 
them, there are some ethical concerns about privacy, and both students and faculty members will need to work early on to test them. Contact Educational Technology.

\section{Appendix B}

Excerpt from First Email to June Course Leaders and Participants:

THE NOW

To state the obvious: This geographical / national / global place and this historical moment are themselves profoundly overwhelming and disorienting (and a whole lot of other emotionladen things, as well). That will be true for the students you meet in fall (or are teaching now in summer), and, I'm gambling to say, right now it is true for all of us. The devastating events of the past days have brought to the surface (AGAIN) the outgrowths of centuries-long systematic oppression and racism, and have put the spotlight (AGAIN) on the deep rifts in our democracy. It can be hard to work, to focus, to be disciplined about learning things you may not really want to be thinking about to begin with, and the work we're inviting you to do may feel very distant from these realities around us. Take care of your whole selves.

We are only here, in this weird space and with the need to ramp up and retool under time pressure, because of the global pandemic. Whatever our "normal" is has been profoundly upended. We want to recognize that the work you face in shifting your familiar mode of teaching, in becoming a "beginner" in places you have long had expertise and comfort, is itself disorienting and profoundly uncomfortable, anxiety inducing even.

In a face-to-face class, this would be the day I would toss out at least part of the planned agenda to be together with students in recognizing and discussing how they are feeling and what they 
are thinking, perhaps through some guided reflective writing prompts, perhaps through discussion of where we are now in the world and the nation as related to course content. But it would not be the day for business as usual. Having no easy way to make this spontaneous re-prioritizing possible is just one of the great losses, for me, in moving to the virtual / asynchronous, and it's an argument, for me, for complementing a primarily asynchronous course with at least some limited time together in the same virtual space / synchronously. Considering how to prioritize the relationship between the asynchronous parts of your course and some select few strategic and complementary synchronous connections is one of the central themes of this first week in the course. How will you make your courses equitably accessible (which often means making them primarily asynchronous) while building in multiple avenues for fostering social presence?

We look forward to continuing this quest together with you over the coming weeks, and we are thinking of you as you do this challenging work in a challenging time.

Warmly, Leslie 